\title{
El juez multinivel y la transversalidad de garantías Un acercamiento a los escenarios fácticos en América y Europa
}

\author{
Recibido: 1 de junio de 2020 - Aprobado: 19 de junio de 2020 \\ https://doi.org/10.22395/ojum.v20n4la2
}

\author{
Jairo Enrique Lucero Pantoja \\ Universidad de Talca, Talca, Chile \\ jlucero@utalca.cl \\ https://orcid.org/0000-0001-7656-3641
}

\section{RESUMEN}

En el presente texto se abordan el control de convencionalidad y el margen de apreciación como modelos jurídico-políticos de protección de derechos humanos que se derivan de las visiones particulares, necesidades y recursos institucionales que cuentan los Estados de la OEA y el Consejo de Europa respectivamente. De esta manera, se establece que la dignidad humana es el objetivo universal para el eficaz ejercicio de los aparatos de justicia, a pesar de los métodos dispares de integración de derecho internacional. Para este fin, se realiza una investigación descriptiva y explicativa, se emplea la metodología dogmática —clásica de las ciencias jurídicas_- y los submétodos sistemático, analítico y de enjuiciamiento de hecho. En este sentido, se concluye, en primer lugar, que se deben menguar los efectos de soberanía nacional, los cuales limitan la armonización garantística del ordenamiento jurídico. En segundo lugar, se vislumbra un estándar mínimo internacional a través de un espacio constitucional común que dote de facticidad un equilibrio de derechos universalmente protegidos por jueces multinivel.

Palabras clave: corpus iuris interamericano; control de convencionalidad; margen de apreciación; dignidad humana; juez multinivel. 


\section{Multilevel Judge and Transversality of Guarantees Approach to Factual Scenarios in America and Europe}

\section{ABSTRACT}

This article will study the control of conventionality and the margin of appreciation as legal-political models for the protection of human rights derived from the particular visions, needs and institutional resources of the OAS States and the Council of Europe respectively, establishing, notwithstanding the disparate methods of integration of international law, that human dignity is the universal objective for the effective exercise of justice apparatus. For this objective, since a research descriptive and explicative, and used a dogmatic methodologist, and sub methods systematic, analytic and judgment facts, we will conclude that first, the effects of national sovereignty should be diminished, because this limit the guarantee harmonization of the legal system, and then, secondly, build a minimum international standard through a constitutional space common to provide a balance of rights universally protected by multilevel judges.

Keywords: inter-American corpus iuris; conventionality control; margin of appreciation; human dignity; multilevel judge.

\section{0 juiz multinivel e a transversalidade das garantias Uma abordagem dos cenários factuais na América e na Europa}

\section{RESUMO}

Este texto trata do controlo da convencionalidade e da margem de apreciação como modelos jurídico-políticos de protecção dos direitos humanos derivados das visões, necessidades e recursos institucionais particulares dos Estados da OEA e do Conselho da Europa, respectivamente. Desta forma, estabelece-se que a dignidade humana é o objectivo universal para o exercício efectivo do aparelho de justiça, apesar dos métodos díspares de integração do direito internacional. Para este fim, é realizada uma investigação descritiva e explicativa, é utilizada a metodologia dogmática —clássica das ciências jurídicas - e os sub-métodos sistemático, analítico e factual de acusação. Neste sentido, conclui-se, em primeiro lugar, que os efeitos da soberania nacional, que limitam a harmonização da garantia do sistema jurídico, devem ser atenuados. Em segundo lugar, está prevista uma norma mínima internacional através de um espaço constitucional comum que proporcione um equilíbrio de direitos universalmente protegidos por juízes a vários níveis.

Palavras-chave: corpus iuris interamericano; controlo da convencionalidade; margem de apreciação; dignidade humana; juiz a vários níveis. 


\section{INTRODUCCIÓN}

La presente investigación se proyecta en el marco de la exploración jurídica llevada a cabo en el Centro de Estudios Constitucionales de Chile (Cecoch) de la Universidad de Talca, del cual el autor es parte, especialmente el grupo de investigación Living constitution. Dicho esto, considerar al derecho un instrumento de perpetuación de un sistema de organización social difiere sustancialmente de una mirada formalista del mismo, pues esta última acarrea observar el derecho como una herramienta que se cimenta por antonomasia en la conservación —o solidificación — de los elementos jurídicos (Pintore, 2017, p. 51; Schauer, 2009, p. 30)'. Por otro lado, la primera perspectiva no exige la falta de transformación del derecho o la ausencia de interpretación que derive en cambios, sino la continuación de un proyecto deontológico que guía, estructuralmente, al sistema social y político que engendra el ordenamiento jurídico. Asimismo — descartando las miradas formalistas - el derecho, como la sociedad, es dinámico; emprender el objetivo contrario es firmar un inminente fracaso en cuanto a su eficacia.

Ahora bien, aunado a este cambio se ha generado un derrotero esencial del tránsito que se debe continuar en las trasformaciones jurídicas nacionales e internacionales. A pesar de ser tan solo una hoja de ruta - la cual evoluciona en cada paso-, el corazón hallado en el principio pro persona se considera la esencia del desarrollo del derecho, por lo que la progresión y no regresión de garantías humanas y colectivas son los desafíos de esta perspectiva gestada en la ductilidad del derecho. Sin embargo, la fricción entre cuerpos jurídicos nacionales e internacionales y el debate inconcluso de superioridad y aplicabilidad, apertura un quiebre ideológico que dinámicamente se suspende en los Estados en conformidad con los contextos político y económico que estos surten, no sin antes afrontar un mundo globalizado que, en su expansión, pretende la homogeneidad jurídica y —aunque no directamente- garantística en derechos humanos. De esto resultan sistemas porosos de comunicación normativa², potencializados aún más en la era de la indivisibilidad e interdependencia de los derechos ${ }^{3}$.

En este sentido, al observar el cambio y la obtención de máximas garantías de derechos como el horizonte de las nuevas iniciativas de estructuración del derecho universal, nos enfrentamos a dudas pragmáticas devenidas de las importantes

1 Es necesario aclarar que no por ello debemos alejarnos a puntos intermedios de dicotomía formalista y guías valóricas de orientación (Botero, 2006, p. 33), pero cuyo resultado —y es inevitable negarlo- altera la esencia más conservadora del formalismo.

2 En este sentido, García Jaramillo (2016), refiriéndose al sistema interamericano, señala que "[lla idea de soberanía se ha permeabilizado para filtrar al derecho interno tanto estándares normativos formales, provenientes de la jurisprudencia interamericana, de los comités y de otros tribunales, como informales, a partir de la intensificación del diálogo entre las altas cortes nacionales y la Corte Interamericana" (p. 152).

3 Esto lo determinó Naciones Unidas en la Proclamación de Teherán de 13 de mayo de 1968 y en la Resolución 32/130 de 1977 (Vásquez y Serrano, 2011). 
diferencias ideológicas del acontecer del continente americano y europeo: ¿Son los mismos programas de desarrollo jurídico regional los que deben emprenderse en estos dos contextos, o sus cruzadas deben diversificarse para amoldarse a cada una de sus particulares diferencias? ¿Qué tipo de juez aplicador del principio pro persona se genera en cada región? ¿El camino jurisdiccional multinivel deviene de un criterio ideológico exponencial de los derechos humanos o parte de la necesidad de hallar una base de mínimos que acarreen una estructura supraestatal? Trataremos en los siguientes párrafos de dar respuesta a estos cuestionamientos. Este trabajo se divide en dos grandes partes. La primera abordará de manera sucinta la evolución de las estructuras jurídicas comunes regionales y universales a través de la consagración de derechos devenidos de principios supranacionales, mientras que la segunda parte examinará las diferencias existentes entre los sistemas americano y europeo, y a partir de estas se consolidarán respuestas alternativas teórico-fácticas para lograr estructuras normativas fuertes que complementen el espíritu del corpus iuris interamericano.

\section{JUEGO DE FACTORES. SURCANDO REALIDADES CONTEMPORÁNEAS Y UBICANDO PLANOS PROBLEMÁTICOS}

Es de resaltar que, en la actualidad, las relaciones jurídicas intranacionales se encuentran plenamente alimentadas por el gran resplandor de obligaciones internacionales que cada Estado debe cumplir a favor tanto de sus ciudadanos como del resto de individuos. Esto no solo se debe a los acuerdos logrados en el plano expansivo de los derechos humanos tras la consagración de la Declaración Universal de 1948, sino más profundamente por la consolidación del metaderecho ${ }^{4}$ de la dignidad humana como el factor de desarrollo progresivo de garantías a los ya existentes derechos ubicados en los ordenamientos jurídicos nacionales ${ }^{5}$. En este sentido, el catálogo de derechos —otrora puestos en el vaivén de los gobiernos de turno- se convirtieron en su "internacionalización" en un espacio de articulación para el enriquecimiento de su contenido y función de reclamación ante su incumplimiento ${ }^{6}$.

4 Según Amartya Sen (2002, p. 15), si X es un derecho, P(x) se constituye en un metaderecho, siempre que sea una política para garantizar las acciones que conduzcan, en forma progresiva, al ejercicio del derecho $\mathrm{X}$.

5 La dignidad humana, consagrada como un metaderecho, posibilita la reclamación jurídica para que los Estados ejerzan cualquier medida gubernamental encaminada a cubrir las necesidades características del cumplimiento de otros derechos. En este sentido, la dignidad humana como factor de articulación pretende el mínimo menoscabo de los derechos o, en otras palabras, demanda al Estado el uso del máximo de sus posibilidades para efectivizar los derechos consagrados en el ordenamiento jurídico (Abrisketa, 2004, p. 119).

6 Encinas Duarte (2015, pp. 22, 24-25) realiza un importante aporte en relación con la construcción de la demanda internacional frente al pluralismo, tanto social como jurídico. No obstante, advierte que este debe evitar la integración supraestatal, pues mina las democracias del Estado-nación. Así, recomienda la construcción de un "Estado abierto" que, desde las sedes nacionales, responda a la estructura y valores democráticos, así como que optimice el ejercicio de los derechos humanos 
Prueba de ello son los planteamientos de Gerber (1971a, p. 43), quien observó los derechos de igualdad, libertad y fraternidad como contenidos acabados del derecho público, los cuales son, por tanto, elementos orgánicos constitutivos de un Estado concreto $^{7}$. En contraposición, Luigi Ferrajoli (2009, pp. 27-29, 78-79) consideró que los mismos, establecidos en el catálogo de derechos civiles, políticos y sociales, no pertenecen ontológicamente a cada individuo, sino a la ciudadanía como cuerpo abstracto. De esta manera, se vislumbra que la constitucionalización de los derechos fundamentales permitió virar la proyección garantística del paleopositivismo como una facultad del Estado hacia una prerrogativa en teoría fácticamente exigible a cada Estado, no solo por parte de un ciudadano o sector optimo iure, sino de toda persona por su mero estatus de pertenencia a la humanidad.

Así las cosas, es un hecho la formación de una estructura normativa internacional de los derechos humanos y, tras ella, una germinante institucionalización internacional para velar por el orden y la paz mundial (Hobsbawm, 2007, p. 179). Se solidificó, entonces, el reingreso jurídico de la corriente iusnaturalista que impactó contundentemente en las estructuras formales del derecho y, en consecuencia, deterioró la creencia de la unívoca formación-validez normativa por parte del Estado-nación, lo que posibilitó la estigmatizada ductilidad jurídica, o si se quiere, fomentó su carácter expansivo.

Esto permitió superar el problema central del iusnaturalismo que, como bien lo precisaba Kelsen (1993, p. 69), se sostiene en una falacia lógica que consiste en inferir el "deber ser" (lo axiológico) del "ser" (lo ontológico), por lo que se apela a un orden jurídico en el que se deja en un gran subjetivismo su creación y contenido, y se proyecta de forma aleatoria la naturaleza y la razón (Marcone, 2005, p. 126). Ante ello, se establece un nuevo constructo racional posiusnaturalista en el que los derechos fundamentales se vislumbran como mandatos de optimización. No obstante, según Alexy (1988, p. 140) y Aarnio (2000, pp. 593-594), se distinguen tesis de separación fuertes y débiles entre reglas y principios, y desde estas posiciones se ha desarrollado los discursos jurídicos de Dworkin, Atienza, Ruiz Manero y Comanducci (Cianciardo, 2003, pp. 893-897; Lopera, 2004, pp. 235-236; Ruiz, 2012, pp. 152-164).

En esta medida, el organigrama político y social que devino a finales del siglo XVIII con los Estados-nación, mediante el cual se catapultaba a estos como los únicos destinados a velar por la producción normativa, sería una de las propiedades más fuertemente golpeadas al consagrarse un sistema normativo de tendencia universal, cuyo fin se centró en resguardar los mínimos jurídicos que cada Estado debiese respetar de forma trasversal. Un pleno ejemplo de ello es la consolidación de las garantías ius cogens, de los que se derivó la consagración de hechos internacionalmente ilícitos y crímenes internacionales (Casado y Vázquez, 2005, pp. 345-346), y posteriormente

En otra oportunidad el mismo Gerber (1971b, pp. 130-133) los llamó "efectos reflejos" a través de los cuales el Estado regula su actividad mediante el derecho. 
el establecimiento de tribunales ad-hoc ante graves crímenes de guerra y derechos humanos (violación del derecho internacional humanitario) e, incluso, al margen de la esfera institucional. Así, se presentó la exclusión económico-política de aquellas naciones cuyos procederes antidemocráticos obstruían el cumplimiento integral de los derechos humanos ${ }^{8}$.

En este contexto, se posibilita la estructuración de organizaciones continentales y regionales a fin de obtener una base jurídica y política común, capaz de sostener la unificación de ideales, en principio económicos, y posteriormente de estructura social', lo que conlleva a la alineación de los Estados en un mismo norte normativo. Además, esto permite, posteriormente, trascender su fin comunitario a planos jurisdiccionales igualmente comunes, tanto en derecho ordinario (por ejemplo, el Tribunal de Justicia de la Unión Europea [TJUE]) como frente a vulneración de derechos humanos convencionalizados para cada región (por ejemplo, el Sistema Interamericano de Derechos Humanos y el Sistema Europeo de derechos humanos para los Estados miembros del Consejo de Europa).

De esta manera, la tendencia de una justicia global cimentada en la internalización de instituciones supranacionales, cuyo diálogo permeó la sólida estructural clásica de un Estado individual y apartado, guio al Estado por un camino coherente con los marcos normativos comunes regionales y universales. De esta manera, se establecieron estándares de contenido mínimo (Santolaya, 2013, p. 449) que la soberanía nacional debió obedecer y permitir su evolución, así como la maximización a espacios que internamente, incluso, no han sido contemplados.

Así, la pretensión de un mejor mundo jurídico se vislumbró a través del grado de "adecuación" (valga decir, respuesta eficaz) que este tiene frente a las necesidades sociales de las que deviene su creación. Por tanto, la respuesta de perfeccionamiento del derecho también corresponde al nivel de eficacia que este posea a fin de ser armónico tanto en fundamento como en acción. Sin embargo, la ruptura ha sido en el último siglo el motor de arrastre para la trasformación jurídica (aunada la búsqueda de la eficacia y la correspondencia con las necesidades sociales), si se quiere dramática, de las convenciones morales generalizadas de la sociedad (Habermas, 2010, pp. 106-

8 Existen diversos ejemplos de lo mencionado, aunque se diferencian por los fines perseguidos, bien sean económicos o de política interna (por ejemplo, la OEA frente a Cuba en 1962 o la UE frente a Rusia en el escenario suscitado en Georgia en 2008 y Ucrania en 2014) o por el repudio ante evidentes violaciones de DH o DIH (por ejemplo, las invasiones de Israel en la Franja de Gaza —y últimamente Cisjordania — o por la política migratoria de los EEUU en 2018). En este último caso, dicha manifestación puede presentarse a través del Consejo de Derechos Humanos de la ONU, el cual requiere dos tercios de los miembros presentes y votantes de la Asamblea General para suspender los derechos inherentes a formar parte del Consejo a todo miembro implicado en violaciones graves y sistemáticas de DH (Ziegler, 2018).

9 Haciendo necesaria la aclaración que dichos propósitos se postulan teórica y fácticamente de la mano, esto es, en dimensiones integradas. Para mayor profundidad, el estudio de Rodríguez-Pose y Petrakos (2004). 
108). Si bien no se puede asumir como producto innovador tras los juicios de Tokio y Núremberg, es claro que la dignidad — otrora olvidada — asumió el papel protagónico frente a la construcción de un mundo "justo", cuyo contenido refleja legitimidad y exige eficacia social.

La resonancia de esta fuente moral de contenido jurídico ha llevado a que esta se proyecte de manera expansiva en el mundo. En este sentido, es una construcción que no se esconde en límites nacionales (de valor schmittiano), sino que debe su vida a la reproducción, obedecimiento generalizado y trasformación progresista de su fundamento. De esta manera, se retrata la necesidad de formación organizativa que permita, desde un colectivo universal, sostener mínimos evolutivos de lo que debe entenderse como "justo" a partir de la explotación convencional de "dignidad" (Habermas, 2010, pp. 108) que no se retraiga hacia algunos ciudadanos determinados, sino que se direccione a todas las personas habitantes de cada nación sin distingo alguno.

Con todo, en el escenario actual es posible reconocer que el derecho está compuesto tanto por su dimensión formal — como producto integralmente legislativo en el que se reconoce la hegemonía del legislador — como por su dimensión material — que se formula a través de las normas constitucionales indeterminadas en el que operan reenvíos y recepciones a un derecho material prepositivo- (Zagrebelsky, 2008, pp. 6-7).

Bajo estos postulados, se requiere hablar de un derecho constitucional abierto, que no es otra cosa que el reflejo de la crisis de los postulados kelsenianos sobre la naturaleza exclusivamente legislativa de los ordenamientos (Ugarte, 1995, p. 110), y más aún frente al carácter conclusivo que las constituciones forjan sobre sí mismas.

En igual sentido, es importante reseñar que bajo esta dimensión material se justifica la labor del juez como intérprete de este derecho material prepositivo a través del cual se aminoran, teóricamente, las distancias territoriales para dar paso a una confluencia de un "estándar moral esencial" que impide vulnerar ciertos derechos considerados como indisponibles, inalienables e irrenunciables para la vida humana (Zagrebelsky, 2008, pp. 12-15).

Ciertamente, bajo estos contenidos fundamentales coincide el constitucionalismo contemporáneo (Cassese, 2017, p. 177), en donde se posibilita que las jurisdicciones de los distintos Estados puedan generar evaluaciones comparativas, a modo de diálogo horizontal, en el que a través de la jurisprudencia se creen orientaciones comunes con tendencia a la formación de un mínimo común denominador constitucional que permita brindar respuestas a cuestiones de interés general (Zagrebelsky, 2008, p. 16). Este diálogo es un acto de acoplamiento jurídico no obligatorio, pero sí persuasivo. Por el contrario, antagónicamente se produce un diálogo de carácter vertical que surge desde las cortes internacionales hacia las locales. 
Ambas manifestaciones se impulsarían al entrar la segunda mitad del siglo XX, en donde la consolidación — primigeniamente económica — de grupos de Estados regionales, brindarían el sostén institucional para la eficacia de la nueva perspectiva jurídico-moral devenida de la dignidad humana. La "comunidad europea del carbón y del acero" fue la elaboración real de organización supranacional que posteriormente se trasformó en Unión Europea. Esta sería el único ejemplo de la existencia de un semisistema de federación supranacional que albergaría los primeros pasos del constitucionalismo multinivel (Pernice, 2012, p. 16).

Ahora bien, el constitucionalismo abierto es, en la actualidad, una necesidad vital en la que los órganos constitucionales, a través de las normas constitucionales tipo principio $-\mathrm{y}$ sin desconocer las diferencias ${ }^{10}$ que se puedan presentar en los distintos sistemas de garantía constitucional-, han empezado a generar un círculo de relaciones de intercambio de experiencias, de diálogo fluido y comprensión recíproca principalmente en materia de derechos fundamentales. De tal forma, este diálogo presupone estándares mínimos de homogeneidad y congruencia sobre los textos jurisprudenciales, lo que permite darle sentido diacrónico a las propias constituciones nacionales.

No obstante, deben tenerse en cuenta posiciones disidentes frente a la pretensión de "universalidad de derechos" como las presentadas por Pegoraro y Delgado (2001), quienes afirman que "son fruto de visiones antihistóricas y contradictorias de la práctica cotidiana" (pp. 41-43, 51). En esta medida, incluso los derechos fundamentales "obedecen a las necesidades de las sociedades en un momento histórico" y, por tanto, están destinados a "la protección de la persona humana atendiendo a sus condiciones reales al interior de la sociedad, y no al individuo abstracto" (Pegoraro y Delgado, 2001). Aun así, el mismo Pegoraro (2002, p. 403) reconoce la existencia de un fenómeno de circulación, recepción e hibridación de los modelos de justicia constitucional, pues tratándose, por ejemplo, del instituto de control de constitucionalidad, ha tenido una "impetuosa expansión" en el siglo XX, aun cuando ha nacido de orígenes diferentes (modelo francés, americano, austriaco, o híbrido). De esta manera, da cuenta de la comunicación exuberante de los sistemas jurídicos en un mundo hiperconectado que profundiza los lazos normativos históricos de cada sociedad.

Si bien se reconoce este diálogo como medio para la universalización de ciertos contenidos de normas tipo principio, es relevante considerar que la aspiración de la globalización del derecho constitucional se ve limitado en la presente coyuntura de soberanías impostergables y políticas nacionales de carácter imperial. Por ello, es inalcanzable aquel oasis jurisdiccional que permita abarcar tendencias universales garantistas (Cassese, 2017, pp. 176-178) de patrimonio común. En tal medida, la constitución de un ordenamiento de ordenamientos pasa por abrir la pirámide kelseniana y

10 Por ejemplo, entre sistemas common o civil law, judicial review o justicia constitucional, entre otras. 
corregir del mal entendimiento de la soberanía el objetivo garantista que se instituye en los Estados en un mundo que exige comunidad jurídica y garantista ${ }^{11}$.

Con este escenario rápidamente examinado — construido entre matices jurídicos y coyunturas sociales diversas-, la consagración de un sistema normativo regional capaz de ser establecido en su totalidad como una estructura jurídico-institucional común que se derive a partir de esta derechos fundamentales transversales y aplicabilidad jurisdiccional homogénea en cada territorio, es aún un desafío tanto para América como para Europa, ya sea desde el prisma de consolidación per se en cuanto a acuerdos políticos internos que permitan un control y diálogo normativo transversal, así como desde el fin institucional en equidad y sin jerarquías que derive en herramientas que eviten la hegemonía de valores, principios y construcciones jurídicas de un Estado por sobre otros ${ }^{12}$.

Es en esta medida que nuestra misión será contemplar dos respuestas acordes a dos realidades diferenciadas, en donde el objetivo sea uno solo: la eficacia de los derechos.

\section{REALIDADES Y SOLUCIONES. ARRIBANDO AL JUEZ MULTINIVEL EN LOS ESCENARIOS AMERICANO Y EUROPEO}

En primera medida, como bien lo resaltamos anteriormente, los caminos de ordenación normativa e institucional regionales entre Europa y América son bifurcados. Esto se debe a las plenas diferencias que los dos espacios estatales comparten, tanto en su proyección organizativa-comunitaria como en sus relaciones político-económicas.

En este sentido, podemos considerar que la influencia generada en el contexto europeo de naciones como Alemania, Francia e Inglaterra (Kundnani, 2015) se ve sopesada en el Parlamento Europeo, el cual está bastante polarizado en cuanto a la intervención democrática de los europarlamentarios que representan los intereses particulares de los Estados de los que provienen. Por otro lado, la influencia de Estados Unidos en el contexto americano es desbordante, pues esta es capaz de diezmar los esfuerzos generados a partir de la Organización de Estados Americanos e imposibilitar la efectividad requerida por su órgano contencioso (Bobadilla, 2006, p. 22; Benítez, 2006, p. 9).

En este mismo orden de ideas, debemos recordar que si bien existió en América un factor de unidad cimentado en los movimientos políticos poscoloniales que

11 Prueba de ello es como el propio Jean Bodin (2006), creador del concepto de soberanía, reprochaba una concepción absoluta de "soberanía del Estado", esto por cuanto en sus Seis Libros de la República, reconocía expresamente que la soberanía tenía como límite el "derecho de gentes", hoy representado por el constructo del Derecho Internacional de los Derechos Humanos.

12 Esto último, por supuesto, se cimenta en el repudio de una hegemonía jurídica basada en el predominio valórico de un Estado, esto es, no argumental, razonado ni consensuado. Sobre este tema, son interesantes las reflexiones de Moreno y Serrano (2009, pp. 28-29). 
devendrían en la independencia de los países (suscitados en la primera mitad del siglo $\mathrm{XIX)}$, este sentimiento no es equiparable al paneuropeísmo originado a partir de Carlo Magno y su figura del emperador Augusto en el año 800 d.C. Este sentimiento marcaría la identidad común europea que posteriormente sería nutrida ideológicamente por pensadores como Saint-Simon y su "reorganización de la sociedad europea" en 1823, la construcción de la entente cordiale de Guizot y Aberdeen en la década de 1840, la Europa federada de Proudhon en 1863, la gran República Occidental de Comte, la promulgación de los Estados Unidos de Europa de Víctor Hugo en 1849, la Liga de la Paz y la Libertad —asociación defensora del federalismo europeo creada en 1867 por Charles Lemmonier (Gil, 2017, p. 4) —, la crusade for Pan-Europe de Von Coudenhove-Kalergi de 1923 y, finalmente, el discurso presidencial del francés Aristide Briand en 1929 sobre el avance de una Europa con un modelo federal que conllevaría a una idea más sólida de organización comunitaria que, si bien albergaba sus diferencias, guardaría una unidad regionalizada. De esta forma, Víctor Hugo concluiría en el Congreso de la Paz el espíritu de unidad y diferencia europeo - tal vez anunciando poética y anticipadamente lo que se afrontaría como "margen de apreciación"—, al precisar que:

sin perder sus cualidades distintivas y vuestra gloriosa individualidad, ustedes se fundirán estrechamente en una unidad superior, y constituirán la fraternidad europea, absolutamente como Normandía, Bretaña, Borgoña, Lorena, Alsacia, todas nuestras provincias, se unieron a Francia. [... L Llegará un día en que no haya más campos de batalla que los mercados que se abran al comercio y los espíritus que se abran a las ideas. [... Llegará un día dónde las balas de cañón y las bombas sean reemplazados por los votos, por el sufragio universal de los pueblos, por el venerable arbitraje de un gran Senado soberano que será en Europa lo que el Parlamento es en Inglaterra, lo que la Dieta es en Alemania, lo que la Asamblea Legislativa es en Francia. (Torres, 2017, p. 80)

En este contexto, es previsible considerar que en Europa la primera seudoconstrucción institucional supranacional se gestó tras el llamado del Zar Nicolás II frente a la consolidación del Tribunal de la Haya o Corte Permanente de Arbitraje en 1898, a fin de resolver los conflictos (preponderantemente bélicos) que afectasen a los Estados, entidades e individuos. Este esfuerzo, no obstante, adoleció persistentemente de eficacia al no contar con los instrumentos suficientes para hacer cumplir sus resoluciones, especialmente cuando los contenciosos afectaban a grandes potencias (Pereira y Warnier, 2011, p. 107). Esta problemática se vio sustancialmente resuelta con las jurisdicciones europeas actuales con gran poder resolutivo (TJUE y TEDH principalmente, aunque también administrativamente a través del Consejo Europeo, el Consejo de Ministros, la Comisión Europea e incluso el Comité Económico y Social Europeo).

Por otro lado, las actuales sentencias y directrices jurisprudenciales de la Corte Interamericana de Derechos Humanos tienen en su aplicabilidad un mandato de buena fe estatal (Álvarez, 2007, p. 22; González, 2014, pp. 141, 144-148). No existen, por tanto, espacios de presión eficaces ante su incumplimiento, por lo que la OEA proyecta 
levemente en su consejo permanente la primigenia idea de una Institución constante de ordenamiento regional. Así, vislumbra metas políticas como la erradicación de la pobreza, la garantía del derecho a la salud, la equidad de género, entre otras. Asimismo, tiene fines institucionales para algunos de sus órganos descentralizados, tales como el Consejo Interamericano para el Desarrollo Integral, la Organización Panamericana de la Salud y la Comisión Interamericana de Mujeres, cuyas disposiciones resolutivas no poseen la rigurosidad de obedecimiento o eficacia que tienen las directrices proferidas en las instituciones de la comunidad europea.

En esta medida, las contingencias derivadas del planteamiento organizativo europeo a finales del siglo XIX frente a la eficacia de sus instituciones supraestatales fueron solucionadas en buena medida al finalizar el siguiente siglo. Pero estas siguen siendo problemáticas persistentes para América y sus construcciones organizativas de más de siete décadas (Ramírez, 2011, pp. 227-233; Kletzel y Barretto, 2015, pp. 23-59).

Con todo, ambos sistemas regionales se enfrentan a dos paradigmas en su horizonte jurídico evolutivo, esto es, la corriente de constitucionalización del derecho internacional o aquella que aboga por la internacionalización del derecho constitucional. Cualquiera que sea tomada, ninguna es adquirida en forma pura, sino que es complementada en imprescindibles matices de conexión local-global que hoy los Estados no pueden desconocer en sus innumerables relaciones político-económicas, lo que conduce inevitablemente a la difuminación de las barreras y conceptos propios de lo nacional frente a lo internacional (Slaughter y Burke-White, 2007, pp. 110; Núñez, 2012, pp. 2-3).

Pese a ello, nos encontramos ante dos realidades visiblemente diferenciadas. Consecuentemente, se han puesto en marcha dos desarrollos estructurales, supranacionales, jurídicos e institucionales distintos en estos dos continentes. En este sentido, para dar una efectiva respuesta hacia la resolución de una jurisdicción regional guiada por la conjunción de las corrientes iusnaturalista y axiológica de los derechos humanos - y más profundamente de la consolidación de los derechos fundamentales trasversales o los destinados a la ciudadanía universal (Ferrajoli, 2009, p. 336)—, debemos enfocar nuestra solución desde dos perspectivas. Cada una resolvería las problemáticas persistentes en las esferas regionales a través de las realidades históricas sumergidas en sus derechos (Agudo y Vázquez, 2014, p. 399).

\section{Programa teórico para Europa}

Observados los lineamientos sustanciales de la Unión Europea soportados en su construcción histórica de colectivización regional, hemos de anticipar que la lógica de esta organización se cimenta en la fortaleza de sus instituciones, así como en la legitimidad de sus resultados. Esto no solo se hace con el fin de brindar solidez 
jurídica a sus resoluciones, sino de legitimar los mecanismos que sean necesarios para hacerlas eficaces.

Como reflejo de ello, acontece la paulatina formación institucional del proyecto de Estado federal que por más de dos décadas ha emprendido la sociedad europea, pues desde su consolidación como estructura supraestatal a través del Tratado de Maastricht (Comunidad Europea, 1992) ${ }^{13}$ —modificado por los tratados de Ámsterdam (Unión Europea, 1997), Niza (Unión Europea, 2001) y Lisboa (Unión Europea, 2007)— ha propiciado espacios de construcción de una red institucional común. Por tanto, es necesaria la formulación de una regulación trasversal, pues hasta ahora está pendiendo en la cúspide la obtención de una carta superior de derechos constitucionales para toda la comunidad europea.

Este último paso se ha visto obstaculizado en la medida en que, si bien las instrucciones jurisdiccionales de los dos tribunales europeos (TEDH y TJUE) son plenamente funcionales en las correspondientes administraciones y tribunales nacionales, la autorización democrática del diálogo de fuentes ha sido socavada con el rechazo por parte de Francia y Holanda de una constitución europea que diese paso a una interrelación jurídico-institucional federada (Pernice, 2012, p. 16).

A esto se debe aunar la gran conmoción político-institucional que, desde junio de 2016, ha generado el proceso de salida de Gran Bretaña de la Unión Europea. Si bien este proceso no afecta jurídicamente su permanencia en el Consejo de Europa y, por ende, tampoco sus compromisos adquiridos con la suscripción del Convenio Europeo de Derechos Humanos, las garantías que en este se postulan van enteramente de la mano, para su eficacia, de políticas de tráfico migratorio que sí se verán limitadas por la descoordinación provocada con el Brexit, principalmente en cuanto a la regulación de la Unión que se mantendrá aplicable y los plazos para que dicha salida realmente se efectúe (Tomás, 2017, pp. 1179-1183).

Ahora bien, no es sorpresivo que, una vez efectivizada dicha salida, la denuncia del convenio no será un camino tan difícil de abordar, más aún cuando se ha generado una férrea oposición a las indemnizaciones que el Tribunal Europeo de Derechos Humanos [TEDH] ha exigido al Estado británico por los hechos cometidos bajo la Anti-terrorism, Crime and Security Act (2001), lo cual ha sido señalado como una intromisión en las políticas nacionales de defensa ${ }^{14}$. Para ello, debemos recordar que a través de las

13 Este integró los tres pilares que dieron vida a Unión Europea como súper estructura estamental, a saber, el Tratado de Paris, constitutivo de la Comunidad Europea del Carbón y del Acero (CECA, 1951), el Tratado de Roma constitutivo de la Comunidad Europea de la Energía Atómica (EURATOM, 1957) y el Tratado de Roma, constitutivo de la Comunidad Económica Europea (CEE, 1957).

14 La mencionada ley británica ha generado, según Human Rights Watch (2004, pp. 10-17; 2005, pp. 4-5), graves discriminaciones contra personas extranjeras, produciendo, además de las repercusiones jurídicas ante violaciones de derechos humanos, un costo indefinido derivado de la ruptura social enmarcada en la ideología del enemigo interno, produciendo, por ejemplo, bajos estándares de prueba para condenar actos terroristas, insuficiente supervisión judicial y detenciones indefinidas. 
sentencias del TEDH A. y otros contra Reino Unido (2009), así como la proferida en contra de Macedonia bajo el rótulo El-Masri contra Ex-República Yugoslava de Macedonia (2012a), se determinó la condena a los Estados por participar en procedimientos de restricción de libertad irregulares, actos de tortura y entrega a una jurisdicción extranjera sin el cumplimiento de las reglas señaladas tanto por el ordenamiento interno macedonio como por, principalmente, disposiciones del Pacto Internacional de Derechos Civiles y Políticos [PIDCP] (Asamblea General de las Naciones Unidas, 1966) y el Convenio de Ginebra (Naciones Unidas, 1949). La extracción de los demandantes fue motivada por la supuesta implicación en acciones de carácter terrorista, lo cual se denominó jurisprudencialmente, así como en informes de DH, como o "entrega extraordinaria" (extraordinary renditions). Esta práctica se repitió en otros fallos del TEDH, por ejemplo, Babar Ahmad y otros contra Reino Unido $(2010, \S 113)$ y Othman Abu Qatada c. Reino Unido (2012b, $\oint 185)^{15}$.

Así las cosas, el ejercicio de un juez multinivel que permita el vislumbramiento de una justicia material enfocada en el real respeto de derechos proclamados por la Unión Europea se posibilita por medio de las instituciones ya existentes en la Unión, tal como la acción del Consejo de Ministros en la ejecución de las sentencias del TEDH a partir del 46.2, 46.3, 46.4 y 46.5 del Convenio Europeo de Derechos Humanos (Consejo de Europa, 1950; López, 2013, p. 175; Ferrer, 2018, pp. 860 872). No obstante, figuras como el "margen de apreciación" son elementos que recuerdan la falta de concreción de un Estado federal. Este debe sujetarse aún a las dinámicas histórico-jurídicas de cada nación antes de plantear consolidar una garantía, la cual puede ser evidente frente a la racionalidad expansiva y armónica de la Convención, pero que necesariamente debe esperar al estándar mínimo de "comprensión social" para su exigibilidad y aplicabilidad.

Es con todo ello que, a manera de corolario, se puede afirmar que en el sistema europeo es plenamente identificable la existencia de un juez multinivel debido a la eficacia de las instituciones europeas, pese a que el plan regionalizador de un Estado federal que permita la constitucionalización de las funciones judiciales desde un marco normativo regional aún es un reto del sistema.

\section{Programa teórico para América}

En primera medida, debemos anticipar que las instituciones devenidas de la Carta de la OEA, al no poseer una estructura regulativa rigurosa que permita colegir la existencia de un sistema ordenado y eficiente de administración regional, impiden a la postre que

15 Es menester precisar que esta práctica se extendió por toda una década posterior al 11/S, devenido de una orden clasificada de la Presidencia de los Estados Unidos que permitía a la Agencia Central de Inteligencia (CIA) capturar en el extranjero a personas que figuraran en una lista de sospechosos de terrorismo internacional de corte yihadista (López, 2015, pp. 95-112; López, 2018, p. 21) y con la connivencia de varios países aliados, entre los que se destacan los pertenecientes al Consejo de Europa. 
el marco normativo existente, siendo el más preponderante la Convención Americana de Derechos Humanos [CADH], tenga en sí mismo un poder fáctico de aplicación a nivel nacional, más allá de su obligatoriedad normado. Este hecho se ha visto someramente resuelto por la intervención del Sistema Interamericano de Derechos Humanos, el cual tan solo ha emitido 354 sentencias desde su creación como órgano contencioso el 22 de mayo de 1979'6 (Corte Interamericana de Derechos Humanos, 2018). En este sentido, ha marcado una diferencia enorme con el proferimiento, regularidad y cotidianidad jurisdiccional existente por su homónimo en Europa. En el año 2016, el TEDH había decretado cerca de 19.565 sentencias desde su creación en 1959 (Consejo de Europa, 2016a, pp. 4-5; Consejo de Europa, 2016b, pp. 5-6, 8; Mediavilla, 2017). Solo en el año 2017, se profirieron 1.068 sentencias, 56.250 demandas pendientes y un promedio de dictación de sentencia en treinta meses (Viana, 2018).

Con base en este fenómeno de falta de empoderamiento regional, la Corte IDH ha debido implementar consecuentemente diversos instrumentos jurisdiccionales a fin de dar cumplimiento a la Convención y a sus sentencias. Un importante pinino se consolidó mediante la Opinión Consultiva 5/85 (CIDH, 1985) (referente a la colegiación obligatoria de periodistas), en donde consideró que "si a una misma situación son aplicables la Convención Americana y otro tratado internacional, debe prevalecer la norma más favorable" (§ 52). Así las cosas, como lo asegura Ferrer Mac-Gregor (2011, p. 532), la exigencia de no aplicar el "estándar mínimo" creado por la Corte IDH, privilegiando otra disposición más favorable devenida del ordenamiento interno o una fuente internacional, en el fondo implica aplicar el mandato interamericano. Posteriormente, a través de la Opinión Consultiva OC-6/86 la Corte IDH (1986) estableció un límite al poder jurídico del ordenamiento normativo interno y proyectó alcances jurídicos al cuerpo convencional y a las sentencias interamericanas incluso más relevantes a los de la mera ley. De esta manera, precisó que "[l]a expresión leyes, en el marco de la protección a los derechos humanos, carecería de sentido si con ella no se aludiera a la idea de que la sola determinación del poder público no basta para restringir tales derechos. Lo contrario equivaldría a reconocer una virtualidad absoluta a los poderes de los gobernantes frente a los gobernados" (Corte IDH, Opinión Consultiva OC-6/86, 1986, § 27).

Paralelamente, la Corte IDH consolidó un criterio evolutivo en el contenido de la Convención ADH y los constructos jurídicos incoados en sus sentencias, expresados, verbigracia, en la Opinión Consultiva OC-16/99 (CIDH, 1999):

Esta orientación adquiere particular relevancia en el Derecho Internacional de los Derechos Humanos, que ha avanzado mucho mediante la interpretación evolutiva de los instrumentos internacionales de protección. Tal interpretación evolutiva es

16 Se debe precisar que la Comisión Interamericana de Derechos Humanos fue creada en 1959 e inició sus funciones en 1960, cuando el Consejo de la OEA aprobó su estatuto y eligió sus primeros miembros, pero sin tener características contenciosas. 
consecuente con las reglas generales de interpretación de los tratados consagradas en la Convención de Viena de 1969. Tanto esta Corte, en la Opinión Consultiva sobre la Interpretación de la Declaración Americana de los Derechos y Deberes del Hombre (1989), como la Corte Europea de Derechos Humanos, en los casos Tyrer versus Reino Unido (1978), Marckx versus Bélgica (1979), Loizidou versus Turquía (1995), entre otros, han señalado que los tratados de derechos humanos son instrumentos vivos, cuya interpretación tiene que acompañar la evolución de los tiempos y las condiciones de vida actuales. $(\S 114)^{17}$

Finalmente, el punto culmen de este transcurso de trasversalidad convencional en los ordenamientos jurídicos internos desarrollado por la Corte IDH se halla en el denominado control de convencionalidad. Desde su nacimiento, tras el fallo Almo-nacid Arellano et al. vs. Chile $(\mathrm{CIDH}, 2006)^{18}$, propició el espíritu de lo que a la postre se consignaría como el corpus iuris interamericano. Este se asienta en el objetivo de que las sentencias de la Corte IDH gocen de la misma eficacia directa y efecto útil que la Convención ADH (Ferrer Mac-Gregor, 2013, §43; Nogueira, 2016, p. 5). De esta manera, se articula en un cuerpo normativo unificado de contenido dúctil a través de la irradiación indirecta del efecto erga omnes de la sentencia ${ }^{19}$.

Si bien esta disposición tiene su génesis en el artículo 68.1 de la Convención ADH $(\mathrm{OEA}, 1969)^{20}$, en el que se consolida la eficacia vinculante de las sentencias para los Estados miembros que hayan sido partes del proceso, posee una diferencia notable con su equivalente europea consagrada en el artículo 46 del Convenio EDH (Consejo de Europa, 1950). La primera convención usa como factor de expansión de vinculatoriedad (hacia los otros países que no fueron parte del proceso contencioso) el "consenso tácito" que, bajo la perspectiva de la Corte IDH, debiese existir jurídicamente en toda América frente a las disposiciones emanadas por el Sistema Interamericano ${ }^{21}$. Esto se

17 En el mismo sentido se destaca la sentencia Yakye Axa vs Paraguay, en donde se precisa que "los tratados de derechos humanos son instrumentos vivos, cuya interpretación tiene que acompañar la evolución de los tiempos y las condiciones de vida actuales. Tal interpretación evolutiva es consecuente con las reglas generales de interpretación consagradas en el artículo 29 de la Convención Americana, así como las establecidas por la Convención de Viena sobre el Derechos de los Tratados" (Corte IDH, 2005, §66- §67).

18 No obstante, el desarrollo de esta figura jurídica en el Sistema Interamericano de Derechos Humanos se gestó a través de diversos pronunciamientos por parte de la Corte Interamericana. El primero de ellos fue en el voto razonado del Juez Sergio García Ramírez en el Caso Myrna Mack Chang vs. Guatemala (Corte IDH, 2003, §27) y posteriormente en el Caso Ti6i vs. Ecuador (Corte IDH, 2004, §3; Olano, 2016, pp. 63-64).

19 Esto podría considerarse una evolución en términos de obligatoriedad del pacta sunt servanda consignado en los artículos 26 y 27 (no invocación del derecho interno como incumplimiento del tratado) del Convenio de Viena sobre el Derecho de los Tratados (Naciones Unidas, 1969).

20 Se añade a la misma el art. 62.3 en donde se señala a la Corte como el intérprete auténtico y final de la Convención, así como el art. 2 en la que se exige a los Estados parte adecuar su derecho interno y la conducta de sus autoridades de acuerdo con la Convención, y consecuentemente a los lineamientos derivados de las sentencias de la Corte.

${ }^{21}$ Para un mayor abordaje, remitirse a las precisiones de la Corte Interamericana de Derechos Humanos en la sentencia Artavia Murillo y otros (fecundación in vitro) vs. Costa Rica (Corte IDH, 2012, §129, §148, §170, §273). También se sugiere consultar Fuenzalida (2015, pp. 182-190) y Cabrales (2016, p. 246). 
debe a la presencia de una comprensión uniforme del derecho en todo el continente devenido de las raíces histórico-institucionales comunes que poseen estos países (Nogueira, 2016, p. 9). Por otro lado, el ejercicio desempeñado por el Tribunal Europeo, si bien aborda las notables semejanzas jurídicas existentes en los países del Consejo de Europa, se centra fundamentalmente en la no omisión de las diferencias jurídicoinstitucionales de los Estados, lo cual — como ya lo precisamos - hace necesario un acto o proceso legitimatorio previo antes de aplicar de manera general o erga omnes una disposición judicial. En este sentido, es necesario el uso del margen de apreciación como figura que brinda a los Estados un espacio de acción jurídico hasta tanto exista, en una coyuntura determinada, un mínimo común de convergencia de los países europeos (Sagüés, 2003, p. 219).

De tal forma, la estructura americana de interrelación regional sostenida principalmente a través del Sistema Interamericano de Derechos Humanos trata, no en vano, contando con los limitados recursos que posee (Comisión Interamericana De Derechos Humanos, 2014, p. 36; González, 2014, pp. 124-126, 143-145; Secretaria General OEA, 2000), de formar un criterio jurídico armonizable de protección. A este objetivo lo han llamado diversos catedráticos el ius commune interamericano, a fin de establecer un orden público interamericano de "mínimos" (Ferrer Mac-Gregor, 2013, § 76) delimitados por la Convención ADH y la jurisprudencia de la Corte IDH.

Ahora bien, pese a la gran innovación teórica que se desprende del desarrollo jurídico del Sistema Interamericano, no podemos obviar el hecho de que, frente a la realidad regional, no deja de ser un proceso de integración forzado de regionalización normativa e incluso institucional, a pesar de las características homogeneizables en cultura jurídica de los países que lo conforman. Como hemos visto, la necesaria práctica legitimatoria de un criterio común normativo generado a través del margen de apreciación (tal como se desprende del TEDH), no solo es reprochado prima facie por la Corte Interamericana, sino que responde a una preocupación estructural del SIDH ante la necesaria eficacia de los mandatos proferidos por su tribunal contencioso. Si este no ejerce su correspondiente integración jurídica (aunque ausente fácticamente), quedaría imperativamente carente de fuerza para impregnar las disposiciones interpretativas devenidas de la Convención. En esta misma medida, este es un claro ejemplo de la figura de control de constitucionalidad.

Un claro ejemplo de lo anterior es como Sagüés (2016, pp. 385-386) diferencia dos modalidades de seguimiento convencional: una represiva, mediante la cual el órgano judicial nacional debe abstenerse de aplicar una norma interna opuesta al corpus iuris interamericano, considerando lo opuesto como "carente de efectos jurídicos desde su inicio" — como lo acontecido en el caso Almonacid Arellano vs. Chile (CIDH, 2006)—22,

22 Se recuerda, sin embargo, la existencia de reglas propias de producción normativa y, por tanto, de validez y vigencia en el ordenamiento jurídico interno, aunque su aplicabilidad —a lo que recurre la Corte IDH—, 
y otra constructiva, ejercida cuando el juez nacional reinterpreta y adapta la norma jurídica interna en conformidad con la Convención y su interpretación por la Corte IDH. No obstante las dos modalidades, ambas, en cuanto derechos esenciales, constituyen limitaciones al ejercicio de la soberanía.

Ahora bien, no podemos estar más alejados de la enquistada corriente dualista que percibe al derecho internacional como un agente contaminante de la pureza del ordenamiento interno y, por ende, de la soberanía nacional en su pleno ejercicio de autodeterminación jurídica. No obstante, no puede omitirse que este siga siendo un conflicto que hace parte del consciente colectivo, más que la doctrina de la política latinoamericana. Bien señala al respecto González Domínguez (2017) que

por un lado, el derecho internacional es supremo en el ordenamiento jurídico internacional, de forma tal que los Estados deben cumplir con sus obligaciones internacionales de buena fe, conforme al sentido corriente que haya de atribuírsele a los términos de un tratado, y atendiendo al objeto y fin de dicho tratado, no pudiendo invocar el derecho interno como justificación para incumplir con sus obligaciones internacionales. (pp. 724-725)

Sin embargo, se constituye en paralelo una "insuperable paradoja" cuando en el derecho interno "la supremacía del derecho internacional se ve relativizada por el principio de supremacía constitucional, siendo posibles los siguientes modelos teóricos de implementación: (i) supra-constitucionalidad; (ii) constitucionalidad; (iii) supralegalidad; o de (iv) legalidad de las normas internacionales" (González, 2017, p. 725)²3.

Por tanto, es demandante que la labor del jurista se focalice en soluciones nacidas de escenarios pragmáticos que nos permitan vislumbrar, como en el caso americano, la escasa cohesión institucional y jurídica de los países que la conforman. Estos se asemejan más a fragmentos territoriales que, aunque nacidos de homogéneas raíces normativas, paralelamente han desechado un ideario político de conjunción de un ordenamiento a escala regional basado en la garantía de derechos fundamentales. Este panorama solo es posible, en la actualidad, por los innumerables fallos insubordinados de la Corte Interamericana al tratar de establecer coercitivamente mínimos garantísticos a la gran sociedad americana mediante sentencias condenatorias.

Es dable pensar, entonces, si ha sido eficaz acudir a lineamientos dogmáticos de expansión de derechos, cuyo peso jurídico reposa en la coerción interamericana de sus sentencias y no en la convicción filosófica de valores jurídicos en derechos humanos. En este sentido, es necesario plantearse otras alternativas que refuercen esta posición a través de otras herramientas más cercanas a la cultura "internista" y "positivista" americana.

que es su efecto cierto en la sociedad, se ve claramente contravenido por el ejercicio preferente del estándar de derechos interamericano sobre la norma de derecho interno.

23 En el mismo sentido: Sierra Porto (2013, pp. 428-429); Acosta (2016, pp. 17-25); Huertas-Cárdenas (2016, pp. 212-216). 
Es en tal medida que hemos encontrado un "bache fáctico" cuya resolución la podemos plantear en dos vertientes:

1. La iniciativa de consolidación de códigos modelo en áreas como derecho civil, tributario, penal y de procedimiento, ofrecen buenos inicios de integración normativa regional capaz de entrelazar lazos de carácter regulativo que, debido al raigambre iuspositivista de la cultura jurídica latinoamericana, posibilitaría el cubrimiento de una brecha que acortaría el camino hacia la aplicabilidad de parámetros mínimos por parte de los jueces en la región. Estos son consecuentes y se remiten a la Convención ADH y a la jurisprudencia de la Corte IDH (figura 1).

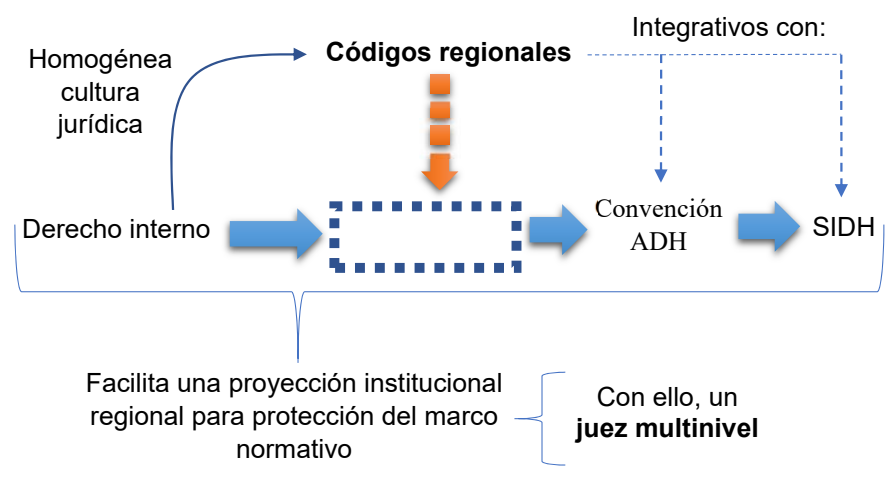

Figura 1. Configuración del juez multinivel en el SIDH

Fuente: elaboración propia.

2. De la misma manera, es plausible coincidir (desde una perspectiva racionalpragmática) que con el establecimiento de un estándar mínimo de derecho ${ }^{24}$ establecido por la Convención y la Corte, y más aún fortalecido con los mencionados códigos ordinarios de carácter regional, existiría de manera más concreta un parámetro o canon de validez frente a la producción normativa interna, lo que genera un escenario más loable de acervo convencional (Nogueira, 2008, p. 570; Nogueira, 2017, pp. 281-282) que no responda solo al cumplimiento de los artículos 1 y 2 de la Convención IDH (OEA, 1969) y los artículos 26, 27 y 31.1 de la Convención de Viena sobre derecho de los tratados (Naciones Unidas, 1969). Antes bien, debe responder efectivamente a las estructuras normativas entrelazadas por los códigos regionales y los nacionales, cuya materia ordinaria esté sujeta o sea coherente con garantías convencionales consagre un espacio propicio para que el principio pro persona sea la efectiva herramienta de uso ante la

24 Para mayor profundidad, remitirse a la sentencia de la Corte Interamericana de Derechos Humanos (2010) Gomes Lund y otros ("Guerrilha do Araguaia") vs. Brasil (§ 177). 
resolución jurisdiccional de conflictos jurídicos de un juez nutrido filosóficamente por el antiformalismo, la tutela judicial efectiva y el razonamiento multinivel.

Con ello, es necesario precisar que la Corte IDH, desde la emisión de la Opinión Consultiva OC-5/85 (CIDH, 1985), estableció que se debe propiciar la "restricción en menor escala al derecho protegido [...] debiendo prevalecer la norma más favorable a la persona humana". Posteriormente, se definió en la opinión separada del juez Rodolfo Piza Escalante como

(un) criterio fundamental (que) [...] impone la naturaleza misma de los derechos humanos, la cual obliga a interpretar extensivamente las normas que los consagran o amplían y restrictivamente las que los limitan o restringen. (De esta forma, el principio pro persona) [...] conduce a la conclusión de que (la) exigibilidad inmediata e incondicional (de los derechos humanos) es la regla y su condicionamiento la excepción. (Corte IDH, Opinión Consultiva OC-7/86, 1986, § 36)

Con ello, Zlata Drnas de Clément (2015, p. 102) observa que el principio pro persona carece de un solo significado, ya que es complejo por su propia naturaleza, su origen, las vías de su aplicación y sus fines ${ }^{25}$. Finalmente, Mónica Pinto (2014) llega a considerarla como la

regla que está en la cúspide del complejo corpus iuris de los derechos humanos que prioriza a la persona humana frente a otros sujetos internacionales, punto de apoyo de la formación de un ius commune transnacional, regla amalgamadora del derecho interno e internacional de los derechos humanos, base de un nuevo ius gentium.

Por otro lado, es necesario aclarar que, si bien el ideario codificatorio regional suscitado a partir del Código Bustamante en 1928 no obtuvo los resultados deseados (Gallegos, 2018, p. 179), debemos percatarnos que en la actualidad, a diferencia de dicha época, el interés preponderante de las políticas nacionales se basa en la adquisición de acuerdos comerciales ${ }^{26}$. Ahora bien, la perspectiva en la que los códigos privados se observaban ausentes de regulación constitucional ha dejado de ser una concreta

${ }^{25}$ En su género, se concibe en un variado espectro jurídico-teórico, desde criterio hermenéutico como criterio interpretativo prevalente en materia de derechos humanos o conjunto de parámetros-guía o directrices para la interpretación y aplicación del derecho de los derechos humanos, hasta norma subyacente o "no enunciada" inherente al derecho internacional de los derechos humanos, pero en todo caso regla de preferencia predominio y principio ordenador que da sentido y jerarquiza al sistema normativo (Drnas de Clément, 2015, pp. 102-103).

26 Debemos recordar que para el momento del planteamiento del Código Bustamante en el $6^{\circ}$ Congreso Panamericano celebrado en Cuba en 1928, se presentaron diversas dificultades (retiro de la delegación estadounidense, no firma de México y Colombia, y gran número de ratificaciones con reservas), motivadas, entre otras, por la pérdida de la hegemonía de la Doctrina Monroe a que durante los 30, la política keynesiana de proteccionismo aplacaría la crisis económica vivida en el momento. Con ello, generó el cerramiento de fronteras comerciales, lo que vendría a consolidar, como es natural, un efecto contrario al deseo de homogenización de normas que permitiesen el ejercicio del libre comercio. Esta situación es ajena a la actual, incluso pospandémica, en la que la regla de oro se encuentra en la transversalización de normas, siempre que estas tengan fines comerciales. 
anomalía jurídica, y han pasado paulatinamente a convertirse en correcciones históricas codificadas. Como se observa en el contemporáneo Código Civil y Comercial de la Argentina (Congreso de la Nación Argentina, 2014), el ordenamiento regulatorio comercial no solo es transversalizado por los parámetros constitucionales, sino también por los instrumentos internacionales de derechos humanos (Lucero, 2019, p. 149), lo cual inspira — de llegar a obtenerse un marco civil regional — la obtención de una hermenéutica regulación civil, benéfica tanto a los intereses comerciales individuales, como a las relaciones jurídicas supraindividuales. Además, implantaría el respeto e integración de los sistemas de garantía de derechos trasnacionales en la norma cotidiana.

Si bien es cierto que no podemos arribar a una construcción ideal de un sistema normativo regionalizado, fundamentalmente por la falta de estructura institucional capaz de sostener el cotidiano ejercicio jurisdiccional de complementación nacional, la coyuntura normativa de códigos regionales devendrá en la incorporación de medidas de interrelacionamiento capaces de confluir con mayor eficacia hacia una organización regional de protección de derechos fundamentales mínimos y regularización pro persona a procesos ordinarios (civil, penal, consumidor, etc.) acordes con una visión supranacional que tienda a una confluencia supraestatal. Por tanto, y para finalizar, debemos rememorar la contingencia vivida en la época romana a través del ius honorarium, el cual pasó de ser el gran baluarte de la era clásica por su carácter antiformalista (reprochado de las XII Tablas) y pragmática para convertirse —en su interpretación dogmática - en un proceso que se constituyó en un obstáculo para el acceso a la justicia de la ciudadanía y plebe romana. Así pues, la etapa justiniana trataría de rescatar dicha practicidad a través del corpus luris civilis, recolectando en un solo cuerpo las institutias y el derecho positivo del codex con su desarrollo pragmático impreso en el digesto. Estos códigos regionales propuestos en este documento deben, por tanto, inspirarse en este hito para rescatar, desde problemáticas cotidianas (sobre todo de índole civil-privado), la naturalidad de la interacción con instituciones internacionales fundadas en la dignidad humana.

\section{CONCLUSIONES}

Hemos llegado a este punto con dos idearios (y si se quiere, caminos) no resolutivos de cómo perfeccionar el sistema jurídico europeo y americano como estructuras regionales capaces de solidificar tanto sus creaciones institucionales como normativas.

Siendo dicho panorama nuestro objetivo regional, es claro que las diferencias sociales, políticas, culturales, institucionales y jurídicas entre América y Europa, impiden que sea usada una misma herramienta para dos contextos con disímiles problemáticas a resolver. De tal manera, el sistema europeo, propietario de una amplia estructura institucional afianzada en su aceptabilidad democrática (tanto parlamentaria o plebiscitaria), permite que sus tribunales posean en sus directrices 
una eficacia mayor que los del sistema americano. En este sentido, es necesario, para la complementación de dicho sistema regional y la posibilidad total del ejercicio multinivel jurisdiccional local, la consolidación de una norma que responda con mayor legitimidad la consagración de un Estado supranacional. De esta manera se brindaría un reparo democrático al Tratado de Lisboa que permita plenamente una jurisdicción unificada en sus parámetros normativos. Por su parte, el sistema americano carece de una estructura institucional y regulación regional que sí posee la comunidad europea, lo cual hace necesaria, por su cultura jurídica proclive al positivismo jurídico, códigos regionales que faciliten la creación argumental y filosófica de juez multinivel y el derecho material. Este hecho blindaría el conocido acervo convencional como una red normativa que se impregnaría en el conocimiento de las instituciones jurisdiccionales nacionales, lo cual supliría de forma temporal la insolvencia institucional regional para dicho control de eficacia jurídica.

De este modo, la consideración regional de un juez dinámico con interpretación ampliada $^{27}$, al que se le permita elaborar lazos y redes normativas en pro de la tutela judicial efectiva, tiene por objeto finalista la renuncia del formalismo exacerbado y la adopción de una actitud garantista ante la realidad pluridimensional, compleja e interdependiente de la naturaleza social del ser humano y, por ende, necesariamente aplicable también en un plano internacional (Agudo y Vázquez, 2014, p. 411). Para ello, es conducente, posterior a la evolución jurídica regional, el avance hacia la conformación de un estándar mínimo internacional de derechos fundamentales que se desprenda de una visión caleidoscópica de la dignidad humana y que abra las puertas a la implementación de un espacio constitucional común.

Así, la incursión de la transformación de un racionalismo epistemológico de "todo y nada" por uno armónico e integralista de "todo y más", pasa por lo que eficazmente consolida Catherine Dupré (2015) al señalar que:

La dignidad humana es un concepto notoriamente difícil de comprender y definir; de hecho, comprenderlo es posiblemente un desafío académico tan grande que lo mejor que podemos esperar podría ser una imagen fragmentada y parcial. Ello se encuentra en una encrucijada compleja de muchas disciplinas, incluida la historia de las ideas, la filosofía, la teología, la sociología, la teoría política y el derecho, siendo posible que tengamos que lidiar con la imagen caleidoscópica típicamente construida por colecciones editadas de ensayos. El atractivo global y los usos de la dignidad humana exigen una perspectiva global, y una serie de estudios han confirmado sus abundantes usos, sin que siempre hayan tenido éxito en iluminar plenamente su desarrollo. (p. 4$)^{28}$

27 Bidart Campos (2000, pp. 17-20) reconocería en dicha interpretación la conjunción de los principios ProActione, Pro-Persona y Favor debilis, como una sola fuente de contenido jurídico de garantías internacionales para el cumplimiento del acceso de la justicia, la tutela judicial efectiva y la dignidad humana.

28 En la versión original: "Human dignity is a notoriously difficult concept to grasp and to define, indeed understanding it is arguably such a scholarly challenge that the best we can hope for might be a fragmented and partial picture. At a complex crossroads of many disciplines, incluiding history of ideas, 
La encrucijada de esta cruzada de transversalización de garantías se centrará, entonces, en el juego coyuntural del panorama jurídico-institucional y de presión social nacional que permitan converger en la sesión de soberanía como reflejo de la ampliación de garantías regionalmente avaladas. Así, se impregna, en esta nueva realidad constitucional ${ }^{29}$, una nueva visión de las fronteras mediante la anulación de los ideales nacionalistas y la implementación del horizonte filosófico del ser humano como el mayor de los proyectos.

\section{REFERENCIAS}

Aarnio, A. (2000). Reglas y principios en el razonamiento jurídico. Anuario da Facultade de Dereito da Universidade da Coruña, 4, 593-602. https://ruc.udc.es/dspace/bitstream/handle/2183/2070/AD-435. pdf? sequence $=1$ EisAllowed $=y$

Abrisketa, J. (2004). Derechos humanos y acción humanitaria. Lege Gordailua.

Acosta, P. A. (2016). Zombis vs. Frankenstein: Sobre las relaciones entre el Derecho Internacional y el Derecho Interno. Estudios Constitucionales, 14(1), 15-60. http://www.estudiosconstitucionales.cl/ index.php/econstitucionales/article/view/300

Agudo, M. y Vázquez, E. M. (2014). Hacia una aproximación crítica entre el derecho constitucional y el derecho internacional. Boletín Mexicano de Derecho Comparado, XLVII(140), 395-416. https://revistas. juridicas.unam.mx/index.php/derecho-comparado/article/view/4876/6227

Alexy, R. (1988). Sistema jurídico, principios jurídicos y razón práctica. Doxa, 5, 139-151. https://doi. org/10.14198/DOXA1988.5.07

Álvarez, R. (2007). Desafíos y retos en el uso del sistema interamericano. Revista Instituto Interamericano de Derechos Humanos, 46, 19-28. https://www.corteidh.or.cr/tablas/R20071.pdf

Asamblea General de las Naciones Unidas (1966, 23 de marzo). Pacto Internacional de Derechos Civiles y Políticos https://www.ohchr.org/sp/professionalinterest/pages/ccpr.aspx

Benítez, R. (2006). Seguridad hemisférica: debates y desafíos. Universidad Nacional Autónoma de México.

Bidart Campos, G. (2000). Las fuentes del derecho constitucional y el principio Pro Homine. En G. Bidart Campos y A. Gil Domínguez (coords.), El Derecho Constitucional del Siglo XXI: Diagnostico y Perspectivas (pp. 11-22). Sociedad Anónima Editora.

Bobadilla, L. (2006). México y la OEA: los debates diplomáticos, 1959-1964. Editorial Secretaría de Relaciones Exteriores México.

Bodin, J. (2006). Los Seis Libros de la República (cuarta edición). Tecnos.

philosophy, theology, sociology, political theory and law, we might have to contend with the kaleidoscopic picture typically constructed by edited collectios of essays. The global appeal and uses of human dignity call for aglobal perspective, and a number of studies have confirmed its abundant uses, without always succeeding in fully illuminating its development".

29 Bien precisaría Javier Pérez Royo (2003) frente a este fenómeno que: "arranca de la política y acaba en la política. Parte de la política porque el proceso constituyente es un proceso político. Y aunque dicho proceso político acaba en una norma jurídica, en la Constitución con sus artículos agrupados en títulos, capítulos y secciones, acaba en ella para volver a la política, para ordenar un proceso de creación del derecho, que es un proceso político protagonizado por entes sociales de naturaleza política o por órganos del Estado de naturaleza asimismo política" (p. 58). 
Botero, A. (2006). Ensayo sobre la crisis de la razón jurídica: (formalismo versus principios y/o valores). Opinión Jurídica, 5(9), 33-61. https://revistas.udem.edu.co/index.php/opinion/article/view/840

British Parliament (2001, 14 de diciembre) Anti-terrorism, Crime and Security Act https://www.legislationline. org/download/id/7976/file/UK_Anti-terrorism_crime_security_act_2001_am2017.pdf

Cabrales, J. M. (2016). Algunas consideraciones sobre los desafíos interpretativos (teóricos y prácticos) del Control de Convencionalidad en México. En J. Mejía, J. Becerra, y R. Flores (coords.). El control de convencionalidad en México, Centroamérica y Panamá (pp. 224-248). Guaymuras.

Casado, R. y Vázquez, E. (2005). La impronta del ius cogens en el proyecto de artículos de la Comisión de Derecho Internacional sobre la responsabilidad de Estado por hechos internacionalmente ilícitos. En M. Vargas Gómez-Urrutia y A. Salinas de Frías (coords.), Soberanía del estado y derecho internacional: homenaje al profesor Juan Antonio Carrillo Salcedo, Tomo I (pp. 343-360). Universidad de Córdoba, Universidad de Sevilla y Universidad de Málaga.

Cassese, S. (2017). Il futuro del diritto pubblico [ponencial. Giornale di diritto amministrativo (pp. 176-178). Università di Roma. https://images.irpa.eu/wp-content/uploads/2011/10/1l-Futuro-del-dirittopubblicol.pdf

Cianciardo, J. (2003). Principios y reglas: una aproximación desde los criterios de distinción. Boletín Mexicano de Derecho Comparado, XXXVI(108), 891-906.

Comisión Interamericana de Derechos Humanos (2014). Universalización del sistema interamericano de derechos humanos (OEA/Ser.L/V/II.152). https://www.oas.org/es/cidh/informes/pdfs/universalizacionsistema-interamericano.pdf

Comunidad Económica Europea (1957, 25 de marzo) Traité instituant la Communauté Économique Européenne - Tratado de Roma https://eur-lex.europa.eu/legal-content/FR/TXT/PDF/?uri=CELEX:1 1957E/ TXTEfrom $=$ ES

Comunidad Europea (1992, 7 de febrero) Tratado de Maastricht https://eur-lex.europa.eu/legal-content/ $\mathrm{ES} / \mathrm{TXT} / \mathrm{PDF} /$ ?uri $=\mathrm{CELEX}: 11$ 1992M/TXTEfrom $=\mathrm{ES}$

Comunidad Europea de la Energía Atómica (1957, 25 de marzo) Treaty the European Atomic Energy - Tratado de Roma https://eur-lex.europa.eu/legal-content/EN/TXT/PDF/?uri=CELEX:1 1957A/TXTEfrom=ES

Comunidad Europea del Carbón y del Acero (1951, 18 de abril) Tratado de Paris https://eur-lex.europa. eu/legal-content/FR/TXT/PDF/?uri=CELEX:1 1951K/TXTEfrom=ES

Conferencia de las Naciones Unidas (1969, 22 de mayo) Convenio de Viena sobre el Derecho de los Tratados https://treaties.un.org/doc/source/docs/A_CONF.39_11_Add.2-E.pdf

Congreso de la Nación Argentina (2014, 8 de octubre). Ley 26.994. Código Civil y Comercial de la Nación. http://www.saij.gob.ar/docs-f/codigo/Codigo_Civil_y_Comercial_de_la_Nacion.pdf

Consejo de Europa (1950, 4 de noviembre). Convenio para la Protección de los Derechos Humanos y de las Libertades Fundamentales https://www.echr.coe.int/documents/convention_spa.pdf

Consejo de Europa (2016a). Convención Europea de Derechos Humanos Overview 1959-2015. Consultado el 20 de mayo de 2020. https://www.echr.coe.int/Documents/Overview_19592015_ENG.pdf

Consejo de Europa (2016b). The European Court of Human Rights in Facts \& Figures. Consultado el 2 de junio de 2020. https://www.echr.coe.int/Documents/Facts_Figures_2015_ENG.pdf 
Corte Interamericana de Derechos Humanos (1985, 13 de noviembre). Opinión Consultiva 5/85 solicitada por el gobierno de Costa Rica. https://www.corteidh.or.cr/docs/opiniones/seriea_05_esp.pdf.

Corte Interamericana de Derechos Humanos (1986, 29 de agosto). Opinión Consultiva OC-7/86 solicitada por Costa Rica https://www.corteidh.or.cr/docs/opiniones/seriea_07_esp.pdf.

Corte Interamericana de Derechos Humanos (1986, 9 de mayo). Opinión Consultiva 6/86 solicitada por el gobierno de la República Oriental del Uruguay https://www.corteidh.or.cr/docs/opiniones/ seriea_06_esp.pdf

Corte Interamericana de Derechos Humanos (1999, 1 de octubre). Opinión Consultiva OC-16/99 solicitada por los Estados Unidos Mexicanos. https://corteidh.or.cr/docs/opiniones/seriea_16_esp.pdf.

Corte Interamericana de Derechos Humanos (2003, 25 de noviembre). Caso Myrna Mack Chang Vs. Guatemala https://www.corteidh.or.cr/docs/casos/articulos/seriec_101_esp.pdf

Corte Interamericana de Derechos Humanos (2004, 07 de septiembre). Caso Tibi Vs. Ecuador https:// www.corteidh.or.cr/docs/casos/articulos/seriec_114_esp.pdf

Corte Interamericana de Derechos Humanos (2005, 17 de junio). Caso Comunidad indígena Yakye Axa Vs. Paraguay https://www.corteidh.or.cr/docs/casos/articulos/seriec_125_esp.pdf

Corte Interamericana de Derechos Humanos (2006, 26 de septiembre). Caso Almo-nacid Arellano et al. vs. Chile https://www.corteidh.or.cr/docs/casos/articulos/seriec_154_esp.pdf

Corte Interamericana de Derechos Humanos (2010, 24 de noviembre). Gomes Lund y otros ("Guerrilha do Araguaia") vs. Brasil https://www.corteidh.or.cr/docs/casos/articulos/seriec_219_esp.pdf

Corte Interamericana de Derechos Humanos (2012, 28 de noviembre). Sentencia para el caso Artavia Murillo y otros (fecundación in vitro) vs. Costa Rica. https://www.corteidh.or.cr/docs/casos/articulos/ seriec_257_esp.pdf

Corte Interamericana de Derechos Humanos (2018). Casos Contenciosos. Consultado el 28 de mayo de 2020. http://www.corteidh.or.cr/CF/Jurisprudencia2/busqueda_casos_contenciosos.cfm?lang=es

Drnas De Clément, Z. (2015). La complejidad del principio pro homine. Revista Doctrina, 12, 98-111. https://www.corteidh.or.cr/tablas/r33496.pdf

Dupré, C. (2015). The age of dignity, human rights and constitutionalism in Europe. Hart.

Encinas Duarte, G. A. (2015). Pluralismo ante la erosión estatal y como exigencia del paradigma de la posguerra. Anuario de Derecho Constitucional Latinoamericano, 21, 15-30. https://revistas-colaboracion. juridicas.unam.mx/index.php/anuario-derecho-constitucional/article/download/41 13/3562

Ferrajoli, L. (2009). Los Fundamentos de los Derechos Fundamentales. Luigi Ferrajoli debate con Luca Baccelli, Michelangelo Bovero, Riccardo Guastini, Mario Jori, Anna Pintore, Ermanno Vitale y Danilo Zolo (4 ${ }^{\text {ta }}$ ed.). Trotta.

Ferrer Mac-Gregor, E. (2011). Interpretación conforme y control difuso de convencionalidad. El nuevo paradigma para el juez mexicano. Estudios Constitucionales, 9(2), 531-622. https://scielo.conicyt.cl/ pdf/estconst/v9n2/art14.pdf

Ferrer Mac-Gregor, E. (2013, 20 de marzo). Voto razonado Resolución Corte IDH sobre supervisión de cumplimiento de sentencia caso Gelman vs. Uruguay. 
Ferrer, J. (2018). La ejecución de las sentencias del TEDH relativas a la Federación de Rusia y a Turquía: ¿han fracasado las reformas del protocolo 14? Revista de Derecho Comunitario Europeo, 61, 853-898 https://doi.org/10.18042/cepc/rdce.61.02

Fuenzalida, S. (2015). La jurisprudencia de la Corte Interamericana de Derechos Humanos como fuente de derecho. Una revisión de la doctrina del 'examen de convencionalidad'. Revista de Derecho, XXVIII(1), 171-192. https://scielo.conicyt.cl/pdf/revider/v28n1/art08.pdf

Gallegos, J. (2018). Algunos aspectos a tener en cuenta en relación con las normas sobre derecho aplicable a la contratación internacional en el anteproyecto de nueva ley chilena de derecho internacional privado. Revista de Derecho, 86(244), 177-213. https://scielo.conicyt.cl/pdf/revderudec/ v86n244/0718-591X-revderudec-86-244-00177.pdf

García Jaramillo, L. (2016). De la constitucionalización a la convencionalización del ordenamiento jurídico. La contribución del 'ius constitutionale commune'. Revista Derecho del Estado, 36(1), 131166. https://doi.org/10.18601/01229893.n36.05

Gerber, K. (1971-a). Sui diritti pubblici (Lucchini L, trad.). En Gerber, K. F., Diritto pubblico (3-87). Giuffrè.

Gerber, K. (1971-b). Lineamenti di diritto pubblico tedesco (Lucchini L, trad.). En Gerber, K. F., Diritto pubblico (89-213). Giuffrè.

Gil, J. (2017). Historia de la integración europea. Universidad Nacional de Educación a Distancia.

González Domínguez, P. (2017). Reconfiguración de la relación entre el derecho internacional de los derechos humanos y el derecho nacional sobre la base del principio de subsidiariedad. Anuario Mexicano de Derecho Internacional, XVII, 717-748. http://dx.doi.org/10.22201/ iij.24487872e.2017.17.11050

González, F. (2014). El proceso de reformas recientes al Sistema Interamericano de Derechos Humanos. Revista Instituto Interamericano de Derechos Humanos, 59, 119-149. https://www.corteidh.or.cr/tablas/ r32982.pdf

Habermas, J. (2010). La idea de dignidad humana y la utopía realista de los derechos humanos. Anales de la Cátedra Francisco Suárez, 44, 105-121. http://www.scielo.org.mx/pdf/dianoia/v55n64/v55n64al.pdf

Hobsbawm, E. J. (2007). Guerra y paz en el siglo XXI. Critica.

Huertas-Cárdenas, J. (2016). Monismo moderado colombiano: examen a la teoría oficial de la Corte Constitucional desde la obra de Alfred Verdross. Vniversitas, 132, 197-234. https://revistas.javeriana. edu.co/index.php/vnijuri/article/view/16569

Human Rights Watch (2004, 24 de junio). Neither just nor effective. Indefinite Detention Without Trial in the United Kingdom Under Part 4 of the Anti-Terrorism, Crime and Security Act 2001. https://www.hrw.org/ legacy/backgrounder/eca/uk/anti-terrorism.pdf

Human Rights Watch (2005, 1 de marzo). Commentary on Prevention of Terrorism Bill 2005. https://www. hrw.org/legacy/backgrounder/eca/uk0305/uk0305.pdf

Kelsen, H. (1993). ¿Qué es justicia? Planeta-Agostini.

Kletzel, G. y Barretto, C. (2015). El desafío de complementariedad en la nueva arquitectura institucional en derechos humanos de América Latina. En M. Rojas, (ed.), Desafíos del Sistema Interamericano de Derechos Humanos. Nuevos tiempos, viejos retos (20-61). Dejusticia. https://www.dejusticia.org/wpcontent/uploads/2017/04/fi_name_recurso_759.pdf 
Kundnani, H. (2015). Carta de Europa: El surgimiento de la 'cuestión alemana'. Revista Estudios de Política Exterior, 163. Consultado el 28 de mayo de 2020. https://www.politicaexterior.com/articulos/ politica-exterior/carta-de-europa-el-surgimiento-de-la-cuestion-alemana/

Lopera, G. P. (2004). Los derechos fundamentales como mandatos de optimización. Revista Doxa, 27, 211-243. https://doxa.ua.es/article/view/2004-n27-los-derechos-fundamentales-como-mandatosde-optimizacion/pdf

López, J. M. (2015). Derecho a la verdad y desapariciones forzadas. Aranzadi.

López, L. (2013). El Sistema Europeo de Protección de Derechos Humanos. En G. Bandeira Galindo, R. Urueña y A. Torres Pérez (coords.), Protección multinivel de derechos humanos (pp. 165-186). Red de Derechos Humanos y Educación Superior.

López, L. (2018). El derecho a la verdad: cla emergencia de un nuevo derecho en la jurisprudencia del Tribunal Europeo de Derechos Humanos? Anuario Iberoamericano de Justicia Constitucional, 22, 11-30. https://recyt.fecyt.es/index.php/AIJC/article/view/69127/41627

Lucero, J. (2019). Propiedad privada y equidad intra y transgeneracional en Latinoamérica. Un conflicto de holística jurídica sin resolver. Revista de Derecho Ambiental, 57, 131-188. https://www.researchgate. net/publication/334223999_Revista_Argentina_de_Derecho_Ambiental

Marcone, J. (2005). Hobbes: entre el iusnaturalismo y el iuspositivismo. Revista Andamios, 1(2), 123-148. http://www.scielo.org.mx/pdf/anda/v ln2/vln2a6.pdf

Mediavilla, M. (2017). Tribunal Europeo de Derechos Humanos, una 'joya' para las libertades fundamentales. Amnistía Internacional. Consultado el 28 de mayo de 2020. https://www.es.amnesty.org/enque-estamos/blog/historia/articulo/tribunal-europeo-de-derechos-humanos-una-joya-para-laslibertades-fundamentales/

Moreno, L. y Serrano, A. (2009). Modelo Social Europeo y políticas sociales: una evaluación formativa institucional. Revista Gestión y Análisis de Políticas Públicas, 2, 11-32. https://www.redalyc.org/ pdf/2815/281521695001.pdf

Naciones Unidas (1949, 12 de agosto). Convenio de Ginebra para aliviar la suerte que corren los heridos y los enfermos de las fuerzas armadas en campaña https://www.ohchr.org/sp/professionalinterest/pages/ ccpr.aspx

Nogueira, H. (2008). Informe en derecho sobre precedentes jurisdiccionales en materia de media prescripción. Revista Ius et Praxis, 14(2), 561-589. http://www.revistaiepraxis.cl/index.php/iepraxis/ article/view/361/305

Nogueira, H. (2017). La fuerza vinculante de las sentencias de la Corte IDH, su valor de precedente y la obligatoriedad de su consideración por los Estados Partes de la CADH. En Nogueira, H. y Aguilar, G., El parámetro de control de convencionalidad, la cosa interpretada y el valor de los estándares de la Corte Interamericana de Derechos Humanos (270-293). Cecoch-Editorial Triángulo.

Núñez, M. A. (2012). Sobre la doctrina del margen de apreciación nacional. La experiencia latinoamericana confrontada y el thelos constitucional de una técnica de adjudicación del derecho internacional de los derechos humanos, En P. A. Acosta Alvarado y M. A. Núñez Poblete (coords.), El margen de apreciación en el Sistema Interamericano de Derechos Humanos: Proyecciones regionales y nacionales (pp. 3-49). Universidad Nacional Autónoma de México, Instituto de investigaciones jurídicas.

Olano, H. A. (2016). Teoría del Control de Convencionalidad. Estudios constitucionales, 14(1), 61-94. http:// dx.doi.org/10.4067/S07 18-52002016000100003 
Organización de Estados Americanos (1969, 22 de noviembre). Convención Americana sobre Derechos Humanos https://www.oas.org/dil/esp/tratados_b-32_convencion_americana_sobre_derechos_ humanos.htm

Organización de Naciones Unidas (1948, 10 de diciembre). Declaración Universal de los Derechos Humanos. https://undocs.org/es/A/RES/217(III)

Pegoraro, L. (2002). La circulación, la recepción y la hibridación de los modelos de justicia constitucional. Anuario Iberoamericano de justicia constitucional, 6, 393-416. https://dialnet.unirioja. es/descarga/articulo/1975594.pdf

Pegoraro, L. y Delgado, J. (2001). Derechos 'fundamentales': consideraciones sobre la elaboración del concepto y su implicación positiva en el contexto del constitucionalismo contemporáneo. Revista Derecho del Estado, 10, 41-52. https://revistas.uexternado.edu.co/index.php/derest/article/ view/865/820

Pereira, E. y Warnier, I. (2011). Convergencia y fragmentación en el sistema jurídico internacional. Revista Derecho y Justicia, 1, 91-123. https://doi.org/10.29344/07196377.1.931

Pérez Royo, J. (2003). Curso de derecho constitucional. Marcial Pons.

Pernice, I. (2012). La dimensión global del Constitucionalismo Multinivel Una respuesta legal a los desafíos de la globalización. Instituto Universitario de Estudios Europeos, Serie Unión Europea y Relaciones Internacionales, 61, 5-29. https://repositorioinstitucional.ceu.es/bitstream/10637/61 16/1/ dimension_pernice_2012.pdf

Pinto, M. (2014). International Institutions and the Rule of Law. Panel 5 Supranational institutions and the rule of law (137). www.law.yale.edu/documents/pdf/Pinto_International_Institutions_and_the_ rule_of_law.pdf

Pintore, A. (2017). El formalismo jurídico: un cotejo entre Jori y Schauer. Revista Derecho, 79, 47-75. https://doi.org/10.18800/derechopucp.201702.003

Ramírez, A. (2011). La nueva ruta en las relaciones internacionales: La OEA y el fortalecimiento de los procesos democratizadores en la región. Revista de Derecho, 35, 220-243. http://www.scielo.org. co/pdf/dere/n35/n35a09.pdf

Rodríguez-Pose, A. y Petrakos, G. (2004). Integración económica y desequilibrios territoriales en la Unión Europea. Revista Eure, XXX(89), 63 80. https://scielo.conicyt.cl/pdf/eure/v30n89/art04.pdf

Ruiz, R. (2012). La distinción entre reglas y principios y sus implicaciones en la aplicación del derecho. Derecho y Realidad, 2, 143-166. https://revistas.uptc.edu.co/index.php/derecho_realidad/article/ viewFile/4860/3952

Sagüés, N. P. (2003). Las relaciones entre los Tribunales Internacionales y los Tribunales Nacionales en materia de derechos humanos. Experiencias en Latinoamérica. Revista Ius et Praxis, 9(1), 205221. http://dx.doi.org/10.4067/S0718-00122003000100011

Sagüés, N. P. (2016). Derechos nacionales e internacionales. De la Constitución nacional a la 'Constitución convencionalizada'. En Sagués N. P., (coord.), La Constitución bajo tensión (pp. 389399). Instituto de Estudios Constitucionales.

Santolaya, P. (2013). La apertura de los Constituciones a su interpretación conforme a los tratados internacionales. En Ferrer Mac Gregor E. y Herrera García A. (coords.), Diálogo jurisprudencial en 
derechos humanos entre tribunales constitucionales y cortes internacionales: in memoriam Jorge Carpizo, generador incansable de diálogos (pp. 447-456). Tirant lo Blanch.

Schauer, F. (2009). Thinking Like a Lawyer. Harvard University Press.

Secretaria General de la Organización de los Estados Americanos (2000). El Financiamiento del Sistema Interamericano de Derechos Humanos. http://www.derechos.org/nizkor/la/doc/fina.html .

Sen, A. (2002). El derecho a no tener hambre. Universidad Externado de Colombia.

Sierra Porto, H. (2013). La Constitución colombiana frente al control de convencionalidad. Biblioteca de la Corte Interamericana de Derechos Humanos.

Slaughter, A. M. y Burke-White, W. (2007). The Future of International Law is Domestic (or, The European Way of Law). En J. Nijman y A. Nollkaemper (eds.), New Perspectives on the Divide Between National E International Law (pp. 110-133). Oxford University Press.

Tomás, B. (2017). El Brexit y su impacto en la Europa de los derechos: el desafío británico al Derecho constitucional europeo. Revista de Derecho Político, 100, 1169-1208. https://doi.org/10.5944/ rdp.100.2017.20730

Torres, M. L. (2017). El acervo integracionista en Europa y América: una historia común. Universidad de Salamanca.

Tribunal Europeo de Derechos Humanos (2009, 19 de febrero). Asunto A. y otros c. Reino Unido (Demanda no. 3455/05) https://hudoc.echr.coe.int/eng\# \{\%22itemid\%22:[\%22001 139351\%22]\}

Tribunal Europeo de Derechos Humanos (2010, 16 de julio). Asunto Babar Ahmad y otros contra Reino Unido (Demanda No.s 24027/07, 11949/08, 36742/08, 66911/09 y 67354/09) https://hudoc. echr.coe.int/fre\# \{\%22itemid\%22:[\%22001 -1 10267\%22]\}

Tribunal Europeo de Derechos Humanos (2012-a, 13 de diciembre). Asunto El-Masri c. Ex-República Yugoslava de Macedonia (Demanda no. 39630/09) https://hudoc.echr.coe.int/eng\# \{\%22item id\%22:[\%22001-139035\%22]\}

Tribunal Europeo de Derechos Humanos (2012-b, 09 de mayo). Asunto Othman Abu Qatada c. Reino Unido (Demanda No. 8139/09) https://hudoc.echr.coe.int/eng\#\{\%22itemid\%22:[\%22001-139056\%22]\}

Ugarte, J. (1995). El Sistema Jurídico de Kelsen. Síntesis y Critica. Revista Chilena de Derecho, 22 (1), 109-118. https://repositorio.uc.cl/handle/1 1534/14644

Unión Europea (1997, 2 de octubre) Tratado de Ámsterdam https://eur-lex.europa.eu/legal-content/ES/ TXT/PDF/?uri=CELEX:11997D/TXTEfrom $=$ ES

Unión Europea (2001, 26 de febrero) Tratado de Niza https://eur-lex.europa.eu/legal-content/ES/TXT/ PDF/?uri $=$ CELEX: $12001 \mathrm{C} / \mathrm{TXTE}$ from $=\mathrm{ES}$

Unión Europea (2007, 17 de diciembre) Tratado de Lisboa https://eur-lex.europa.eu/legal-content/ES/ TXT/PDF/?uri=OJ:C:2007:306:FULLEfrom $=$ ES

Vásquez, L. D. y Serrano, S. (2011). Los principios de universalidad, interdependencia, indivisibilidad y progresividad. Apuntes para su aplicación práctica. En M. Carbonell y P. Salazar, La reforma constitucional de derechos humanos: un nuevo paradigma (pp. 135-165). UNAM- Instituto de Investigaciones Jurídicas. 
Viana, I. (2018, 13 de marzo). Estrasburgo: las condenas más importantes contra España en materia de Derechos Humanos. ABC España. https://www.abc.es/espana/abci-estrasburgo-condenas-mas-importantescontra-espana-materia-derechos-humanos-201803131226_noticia.html

Zagrebelsky, G. (2008). El juez constitucional en el siglo XXI. En I Congreso Internacional de Justicia Constitucional y V Encuentro Iberoamericano de Derecho Procesal Constitucional (pp. 3-26). Biblioteca Jurídica Virtual del Instituto de Investigaciones Jurídicas de la UNAM.

Ziegler, J. (2018). Hay que cambiar el mundo. Akal. 